\title{
Investigating the persistence of earnings components and pricing test of abnormal changes in cash
}

\author{
Yaser Ahmadi* and Khosro Faghani Makarani
}

Research and Science Branch, Islamic Azad University, Mazandaran, Iran

CHRON I C LE ABSTRACT

Article history:

Received October 28, 2012

Received in revised format

20 January 2013

Accepted 10 February 2013

Available online

February 122013

Keywords:

Abnormal change in cash

Tehran Stock Exchange

Persistence of earning

\begin{abstract}
This paper investigates the persistence of earnings components and pricing test of abnormal changes in cash for selected firms listed on Tehran Stock Exchange (TSE). The proposed study gathers the necessary data from 166 firms over the period 2004-2012 from firms whose shares were actively traded on TSE market. The study uses Panel data and with the implementation of linear regression technique examines four hypotheses. The results indicate that abnormal negative changes in cash are more persistence than positive abnormal changes. In addition, both positive and negative abnormal changes are more persistence than accruals. Market also has a good perception on abnormal positive and negative changes in cash.
\end{abstract}

(c) 2013 Growing Science Ltd. All rights reserved.

\section{Introduction}

One of the most interesting issues in assessing the performance of financial firm is to look for the quality of earning and any abnormal change in earning may have different consequences on financial statements (Keynes, 1936; Baskin, 1987; Mishkin, 1986). In fact, some people believe that accounting earnings and cash flows could be a good measures to measure the performance of the firms and investigated the role of accounting accruals on earning (Dechow, 1994). Richardson (2003) investigated the relationship between earnings quality and short selling decisions. Richardson et al. (2005) extended the work of Sloan (1996) by building a model to demonstrate that less reliable accruals could lead to lower earnings persistence. They developed a comprehensive balance sheet categorization of accruals and rate each category based on the reliability of the underlying accruals and concluded that there were significant costs associated with incorporating less reliable accrual data in financial statements. 
Ozkan and Ozkan (2004) studied the corporate cash holdings for a selected UK firms by concentrating on the importance of managerial ownership among other corporate governance characteristics such as board structure and ultimate controllers of firms. They presented some evidence of a substantial non-monotonic relationship between managerial ownership and cash holdings. They also observed that the way in which managerial ownership exerts impact on cash holdings did not change with board composition and, in general, the presence of ultimate controllers. The results disclosed that firms' growth opportunities, cash flows, liquid assets, leverage and bank debt were important in determining cash holdings.

Jiang (2007) studied the relationship between contemporaneous stock-price performance and the persistence of accrued earnings, and its effects on the accrual anomaly. The study stated that accrued earnings for stocks that had performed poorly were less persistent in forecasting future earnings than accrued earnings for stocks that had performed, moderately. The study also further reported that a hedge-strategy based on accruals could earn greater abnormal returns following bad-news years. Dopuch et al. (2005) investigated whether sales changes, accruals were influenced by accrual determinants such as firms' inventory and credit policies.

Deshmukh and Vogt (2005) investigated the underinvestment rationale for firm hedging and tested the hypothesis that if firms could hedge to reduce both their reliance on external funds and the volatility of internal cash flow, then their investment spending could be less sensitive to prehedged cash flow. They also reported that among hedgers, investment spending was less sensitive to cash flow when the extent of hedging is higher. According to Dechow et al. (2008) investors correctly price debt and equity issuances/distributions but they often misprice the change in the cash balance in a similar manner to accruals.

Bates et al. (2009) reported that the average cash-to-assets ratio for U.S. industrial firms more than doubled over the period 1980-2006 and reported that while the precautionary motive for cash holdings was important in explaining the increase in cash ratios, there was no consistent evidence that agency conflicts could contributed to the increase. Arslan et al. (2006) investigated the impact of cash holdings in reducing investment-cash flow sensitivity buy looking into some evidence from a financial crisis period in an emerging market. Finally, Almeida et al. (2005) performed a comprehensive study on cash flow sensitivity.

This paper investigates the persistence of earnings components and pricing test of abnormal changes in cash for selected firms listed on Tehran Stock Exchange (TSE). The organization of this paper first presents details of the proposed study in section 2 while the results are given in section 3 and concluding remarks are presented in the last session to summarize the contribution of the paper.

\section{The proposed model}

The proposed study of this paper considers four hypotheses as follows,

1. Negative abnormal changes in cash balances are more persistence than positive abnormal changes in cash balances.

2. Positive abnormal changes are less persistence than accruals.

3. Negative abnormal changes are less persistence than accruals.

4. Market does not have a good perception between abnormal positive and negative changes in cash.

The proposed study gathers the necessary data from 166 firms over the period 2004-2012 from firms whose share were actively traded on TSE market. All selected firms must have equal fiscal year and there should not be any interruption of more than three months in their trading shares. The study uses 
Panel data and with the implementation of linear regression technique examines four hypotheses. In our study, income maintains two components as follows,

$I N C O M E_{t}=A C C R U A L_{t}+F C F_{t}$

where ACCRUAL is calculated accrual for the fiscal year and FCF represent free cash flow. For the purpose of this study, we have decided to divide traditional relationship of balance sheet into the following,

$C A S H+O P A S S E T S=O P L I A B+D E B T+E Q U I T Y$,

where CASH and OPASSETS on the left side of Eq. (2) represent cash and operating assets. In addition, OPLIAB, DEBT and EQUITY represent operating liability, debt and equity of left side of balance sheet. The net operating assets is calculated as OPLIAB-OPASSETS and the change in each component is stated as follows,

$\triangle C A S H+\triangle N E T O P A S S E T S=\triangle D E B T+\triangle E Q U I T Y$.

On the other hand, the change in profitability is described as follows,

$\triangle E Q U I T Y=I N C O M E-D I S T_{-} E Q$.

Combining Eq. (3) and Eq. (4) yields,

$I N C O M E-A C C R U A L=\triangle C A S H+D I S T_{-} D+D I S T_{-} E Q$.

Equivalently, we have

$I N C O M E=A C C R U A L+\triangle C A S H+D I S T_{-} D+D I S T_{-} E Q$.

In order to learn more about the effect of each component of Eq. (6) we may use the following,

$$
\begin{aligned}
& \Delta C A S H_{t}=\alpha_{0}+\alpha_{1} \Delta C A S H_{t-1}+\alpha_{2} C_{A S H}+\alpha_{t-1} \operatorname{INDSIGMA}_{t}+\alpha_{4} \Delta M T B_{t}+\alpha_{5} \Delta S I Z E_{t}+\alpha_{6} \\
& \Delta F C F_{t}+\alpha_{7} \Delta N W C_{t}+\alpha_{8} \Delta C A P E X P_{t}+\alpha_{9} \Delta L E V_{t}+\alpha_{10} D \Delta D I V_{t}+\alpha_{11} \Delta A C Q E X P_{t}+\varepsilon_{t},
\end{aligned}
$$

where $\triangle \mathrm{CASH}_{\mathrm{t}-1}$ is the change on cash from $t-1, C A S H_{t-1}$ is the optimum amount cash, INDSIGMA $t_{t}$ is the standard deviation from the net cash flow, which is calculated from the last five years ended period $t . \triangle M T B_{t}$ is the ratio of market value to book value of total equities, $\triangle S I Z E_{t}$ is the natural logarithm of total assets. In addition, $\triangle F C F_{t}$ is the change in free cash flow, $\triangle N W C_{t}$ is the change in net cash flow, $\triangle C A P E X P_{t}$ is the change in capital expenditures, $\triangle L E V_{t}$ is the change in leverage and, $D \triangle D I V_{t}$ is the change in dividend indicating whether the change is positive or not. Finally, $\triangle A C Q E X P_{t}$ is the change on exported cash for new acquisitions. The value of $A B N \triangle C A S H$ is described into residual and indicates whether the abnormal change in cash is negative or positive. In addition, all independent variables in Eq. (7) represent normal changes in cash. Now we can rewrite Eq. (6) as follows,

$I N C O M E=A C C R U A L+N A C A S H+A B N \triangle C A S H+D I S T \_E Q+D I S T \_D$

In order to estimate abnormal positive/negative cash we use the following,

$$
\operatorname{INCOME}_{t+1}=\beta_{0}+\beta_{1} A C C R U A L_{t}+\beta_{2} N \Delta C A S H_{t}+\beta_{3} A B N \Delta C A S H_{\mathrm{t}}^{+}+\beta_{4} A B N \Delta C A S H_{t}^{-}+\beta_{5}
$$


$D I S T \_E Q_{t}+\beta_{6} D I S T D_{t}+\varepsilon_{t+1}$

where $\mathrm{ABN} \Delta \mathrm{CASH}_{\mathrm{t}}^{+}$and $\mathrm{ABN} \Delta \mathrm{CASH}_{\mathrm{t}}^{-}$are abnormal positive and negative changes on cash, respectively.

In this research, we plan to verify Eq. (9) by using Mishkin (1986) technique, to measure market efficiency in terms of resistance against persistence of earnings obtained in Eq (9). We estimate earning using the following,

${I N C O M E_{t+1}}=\beta_{0}+\beta_{1} A C C R U A L_{t}+\beta_{2} N \Delta C A S H_{t}+\beta_{3} A B N \Delta C A S H_{t}^{+}+\beta_{4} A B N \Delta C A S H_{t}^{-}+\beta_{5}$

$D I S T \_E Q_{t}+\beta_{6} D I S T \_D_{t}+\varepsilon_{t+1}$,

$A R E T_{t+1}=\gamma\left(I N C O M E_{t+1}-\beta_{0}^{*}-\beta_{1}^{*} A C C R U A L_{t}-\beta_{2}^{*} N A C A S H_{t}-\beta_{3}^{*} A B N \Delta C A S H_{t}^{+}-\beta_{4}^{*}\right.$ $\left.A B N \Delta C A S H_{t}^{-}-\beta_{5}^{*} D I S T \_E Q_{t}-\beta_{6}^{*} D I S T \_D_{t}\right)+\varepsilon_{t+1}$,

where ARET is the annual return obtained from different shares. Eq. (10) and Eq. (11) are estimated using Weighted Nonlinear Least Squares.

\section{The Results}

In this section, we present details of our implementation of our results. Table 1 shows details of our observation on some basic statistics,

Table 1

The results of basic statistics

\begin{tabular}{lccccc}
\hline Variable & Mean & Median & Max & Min & Std. Dev. \\
\hline CASH & 0.085 & 0.038 & 0.92 & 0 & 0.14 \\
ICASH & 0.017 & -0.001 & 0.95 & -0.49 & 0.14 \\
INDSIGMA & 0.33 & 0.12 & 4.77 & 0.003 & 0.73 \\
MTB & 3.04 & 1.9 & 17.04 & 0.04 & 3.39 \\
SIZE & 12.69 & 12.63 & 16.17 & 9.14 & 1.27 \\
LEV & 0.69 & 0.69 & 0.98 & 0.15 & 0.187 \\
$F C F$ & 0.088 & 0.119 & 1.68 & -2.89 & 0.52 \\
ACQEXP & -0.01 & 0 & 0.83 & -0.64 & 0.08 \\
CAPEXP & 0.054 & 0.021 & 1.05 & -0.75 & 0.15 \\
NWC & -0.07 & 0 & 0.89 & -2.78 & 0.49 \\
ACCRUALS & 0.028 & -0.02 & 2.99 & -1.68 & 0.54 \\
INCOME & 0.117 & 0.079 & 1.37 & -1.17 & 0.25 \\
DIST_D & 0.072 & 0.024 & 1.99 & -0.69 & 0.29 \\
DIST_EQ & 0.049 & 0.06 & 0.92 & -1.42 & 0.37 \\
NORMALCASH & 0.01 & 0.008 & 0.616 & -0.406 & 0.076 \\
NEGABCASH & -0.021 & -0.0029 & 0 & -0.316 & 0.04 \\
POSABCASH & 0.036 & 0 & 0.825 & 0 & 0.093 \\
ARET & 0.25 & 0.08 & 2.62 & -0.98 & 0.66 \\
\hline
\end{tabular}

The results of Table 1 show that mean and median of $C A S H, A C C R U A L S$ have been positive for all firms, and they mostly have succeeded to accumulate profit over the year. In order to examine the hypotheses of this survey we first need to calculate the normal and abnormal changes on cash flow using the following, 


$$
\begin{aligned}
\operatorname{Cash}_{i, t}=\alpha_{0} & +\alpha_{1} \Delta \operatorname{CaSh}_{i, t-1}+\alpha_{2} \operatorname{Cash}_{i, t-1}+\alpha_{3} \operatorname{INDSIGMA}_{i, t}+\alpha_{4} \Delta \operatorname{MTB}_{i, t}+\alpha_{5} \Delta \operatorname{SIZE}_{i, t} \\
& +\alpha_{6} \Delta F C F_{i, t}+\alpha_{7} \Delta N W C_{i, t}+\alpha_{8} \Delta \operatorname{CAPEX}_{i, t}+\alpha_{9} \Delta L E V_{i, t}+\alpha_{10} D \Delta D I V_{i, t} \\
& +\alpha_{11} \Delta A C Q E X P_{i, t}+\varepsilon_{i, t}
\end{aligned}
$$

In order to perform ordinary regression analysis we first need to choose between pooled and fixed effect models. In our survey, F-statistic is equal to 1.191 with Prob. $=0.075$ and conclude that pooled method is more desirable. Table 2 demonstrates the results of our regression model,

Table 2

The results of regression analysis

\begin{tabular}{lccc}
\hline Variable & Coefficient & t-statistics & Prob. \\
\hline Intercept & -0.001 & -0.50 & 0.617 \\
CASH(-1) & -0.047 & -3.62 & 0.0003 \\
$\triangle C A S H(-1)$ & -0.113 & -2.508 & 0.012 \\
INDSIGMA & 0.034 & 2.074 & 0.038 \\
$\triangle M T B$ & 0.0001 & 0.205 & 0.837 \\
$\triangle S I Z E$ & 0.0682 & 21.91 & 0.000 \\
$\triangle F C F$ & 0.022 & 2.53 & 0.011 \\
$\triangle N W C$ & -0.04 & -5.97 & 0.000 \\
$\triangle C A P E X P$ & -0.016 & -1.37 & 0.168 \\
$\triangle L E V$ & -0.107 & -5.38 & 0.000 \\
$D$ DIV & 0.0038 & 1.72 & 0.084 \\
$\triangle A C Q E X P$ & 0.027 & 0.99 & 0.320 \\
\hline R-Squared=0.413 & Adjusted R-Squared=0.406 & F-statistic=52.73(0.000) & Durbin-Watson=1.88 \\
\hline
\end{tabular}

Based on the result of F-statistic, we can conclude that the model maintains a good fit and DurbinWatson value is within an acceptable limit leading us to conclude that there is no auto-correlation between residuals. Adjusted R-Squared is equal to 0.406, which means the regression describes approximately $41 \%$ of the changes on dependent variable. In summary, we can conclude that the regression provides acceptable results. Next, we also study the following regression model,

$$
\begin{aligned}
\operatorname{INCOME}_{i, t+1} & =\beta_{0}+\beta_{1} \operatorname{ACCRUALS}_{i, t}+\beta_{2} N \Delta \operatorname{CASH}_{i, t}+\beta_{3} A B N \Delta C A S H(+)_{i, t} \\
& +\beta_{4} A B N \Delta C A S H(-)_{i, t}+\beta_{5} D I S T_{-} E Q_{i, t}+\beta_{6} D I S T_{-} D_{i, t}+\varepsilon_{i, t+1}
\end{aligned}
$$

Once more, to perform ordinary regression analysis we first need to choose between pooled and fixed effect models. In our survey, F-statistic is equal to 2.173 with Prob. $=0.000$ and conclude that fixed effect method is more desirable. In addition, Husman test yields F-statistic $=224.78$ with Prob $=0.000$, which confirms fixed effect models. Table 3 demonstrates the results of our regression model,

Table 3

The results of regression analysis

\begin{tabular}{lccc}
\hline Variable & Coefficient & t-statistics & Prob. \\
\hline Intercept & 0.079 & 7.33 & 0.000 \\
ACCRUALS & -0.005 & -0.218 & 0.827 \\
NORMAL CASH & -0.483 & -3.64 & 0.0003 \\
POSABCASH & 0.472 & 4.299 & 0.000 \\
NEGABCASH & -0.546 & -2.387 & 0.017 \\
DIST_D & 0.089 & 2.409 & 0.016 \\
DIST_EQ & 0.091 & 2.124 & 0.034 \\
\hline R-Squared=0.459 & Adjusted R-Squared=0.323 & F-statistic=3.376(0.000) & Durbin-Watson=1.76 \\
\hline
\end{tabular}

Based on the result of F-statistic, we can conclude that the model maintains a good fit and DurbinWatson value is within an acceptable limit leading us to conclude that there is no auto-correlation between residuals. Adjusted R-Square is equal to 0.323, which means the regression describes approximately $33 \%$ of the changes on dependent variable. In summary, we can conclude that the regression provides acceptable results. 


\subsection{Testing the first hypothesis: The persistency of positive and negative abnormal changes in cash}

In order to test the first hypothesis, we look at the coefficients of POSABCASH and NEGABCASH, which are equal to 0.472 and -0.546 , respectively. The results of Wald test yields a difference of 1.018 with standard deviation of 0.292. In addition, F-statistic is equal to 12.148 with Prob. $=0.000$, which means there are meaningful differences among coefficients. The coefficient of negative abnormal change is more than positive one in cash value in terms of quantity. Therefore, we can conclude that negative abnormal persistency is more than positive one.

\subsection{Testing the second hypothesis: The persistency of positive abnormal change in cash and accrual}

In order to test the second hypothesis, we look at the coefficients of POSABCASH and ACCRUALS, which are equal to 0.472 and -0.005 , respectively. The results of Wald test yields a difference of 0.477 with standard deviation of 0.112 . In addition, F-statistic is equal to 18.124 with Prob. $=0.000$, which means there are meaningful differences among coefficients. Therefore, when the coefficient of positive abnormal change in cash is more than accrual value in terms of quantity, then the positive abnormal persistency is more than accrual. Therefore, we can conclude that positive abnormal persistency is more than accrual.

\subsection{Testing the third hypothesis: The persistency of negative abnormal change in cash and accrual}

In order to test the third hypothesis, we look at the coefficients of NEGABCASH and ACCRUAL, which are equal to -0.546 and -0.005 , respectively. The results of Wald test yields a difference of 0.541 with standard deviation of 0.229 . In addition, F-statistic is equal to 5.557 with Prob. $=0.018$, which means there are meaningful differences among coefficients. Therefore, when the coefficient of negative abnormal change in cash is more than accrual value in terms of quantity, then the negative abnormal persistency is more than accrual.

3.4. Testing the fourth hypothesis: Market perception between different persistency of positive and negative abnormal change in cash

In order to test the fourth hypothesis, we look at the following two models,

$$
\begin{aligned}
& \operatorname{INCOME}_{i, t+1}=\beta_{0}+\beta_{1} \operatorname{ACCRUALS}_{i, t}+\beta_{2} N \Delta C A S H_{i, t}+\beta_{3} A B N \Delta C A S H(+)_{i, t} \\
& +\beta_{4} A B N \Delta C A S H(-)_{i, t}+\beta_{5} D I S T_{-} E Q_{i, t}+\beta_{6} D I S T_{-} D_{i, t}+\varepsilon_{i, t+1} \\
& \operatorname{ARET}_{i, t+1}=\gamma\left(\operatorname{INCOM} E_{i, t+1}-\beta^{*}{ }_{0}-\beta^{*}{ }_{1} \operatorname{ACCRUALS}_{i, t}-\beta^{*}{ }_{2}{ }_{2} \Delta C A S H_{i, t}-\beta^{*}{ }_{3} \operatorname{ABN} \Delta \operatorname{CASH}(+)_{i, t}\right. \\
& \left.-\beta_{4}^{*} A B N \Delta C A S H(-)_{i, t}-\beta^{*}{ }_{5} D I S T_{E Q_{i, t}}-\beta^{*}{ }_{6} D I S T_{D_{i, t}}\right)+\varepsilon_{i, t+1}
\end{aligned}
$$

Table 4

The results of regression model on Eq. (14) and Eq. (15)

\begin{tabular}{llllllll}
\hline \multirow{2}{*}{ Coefficient } & \multicolumn{2}{c}{ Predicted model } & & & \multicolumn{3}{c}{ Evaluated model } \\
\cline { 2 - 3 } \cline { 6 - 7 } & Value & t-statistics & Prob. & Coefficient & Value & t-statistics & Prob. \\
\hline$\beta_{0}$ & 0.066 & 6.187 & 0.000 & $\beta_{0}^{*}$ & -0.357 & -3.608 & 0.0003 \\
$\beta_{1}$ & 0.182 & 8.57 & 0.000 & $\beta_{1}^{*}$ & 0.155 & 1.41 & 0.158 \\
$\beta_{2}$ & -0.184 & -1.356 & 0.175 & $\beta_{2}^{*}$ & -2.112 & -2.67 & 0.007 \\
$\boldsymbol{\beta}_{3}$ & $\mathbf{0 . 4 5 8}$ & $\mathbf{4 . 6 6}$ & $\mathbf{0 . 0 0 0}$ & $\beta_{3}^{*}$ & $\mathbf{0 . 3 1 2}$ & $\mathbf{0 . 6 4 6}$ & $\mathbf{0 . 5 1 8}$ \\
$\boldsymbol{\beta}_{4}$ & $\mathbf{0 . 0 1 3}$ & $\mathbf{- 0 . 0 6 2}$ & $\mathbf{0 . 9 5 0}$ & $\beta_{4}^{*}$ & $\mathbf{- 0 . 7 1 6}$ & $\mathbf{- 0 . 6 7 4}$ & $\mathbf{0 . 5 0}$ \\
$\beta_{5}$ & 0.432 & 11.52 & 0.000 & $\beta_{5}^{*}$ & 0.194 & 0.984 & 0.325 \\
$\beta_{6}$ & 0.152 & 4.154 & 0.000 & $\beta_{6}^{*}$ & 0.488 & 2.38 & 0.017 \\
& & & & $\gamma$ & 0.573 & 5.22 & 0.000 \\
\hline
\end{tabular}


To estimate these two equations simultaneously we use Mishkin method (Mishkin, 1986) and the result of LR-statistic is equal to 0.668 with Prob. $=0.716$. Table 4 shows the results of testing predicted and actual regression model using Eq. (14) and Eq. (15). Based on the results of Table 4, we can conclude that market has good perception on change on abnormal positive and negative change.

In summary, the results indicate that abnormal negative changes in cash are more persistence than positive abnormal changes. In addition, both positive and negative abnormal changes are more persistence than accruals. Market also has a good perception on abnormal positive and negative changes in cash.

\section{Conclusion}

In this paper, we have presented an empirical investigation to study the persistence of earnings components and pricing test of abnormal changes in cash for selected firms listed on Tehran Stock Exchange (TSE). The proposed study has gathered the necessary information from 166 firms over the period 2004-2012 traded on TSE market and using panel data and regression analysis examined four hypotheses. The results have indicated that abnormal negative changes in cash were more persistence than positive abnormal changes. We have also found that, both positive and negative abnormal changes were more persistence than accruals and market preserved a good perception on abnormal positive and negative changes in cash.

\section{Acknowledgment}

The authors would like to thank the anonymous referees for constructive comments on earlier version of this paper.

\section{References}

Almeida, H., Campello, M., \& Weisbach, M. S. (2005). The cash flow sensitivity of cash. The Journal of Finance, 59(4), 1777-1804.

Arslan, Ö., Florackis, C., \& Ozkan, A. (2006). The role of cash holdings in reducing investment-cash flow sensitivity: Evidence from a financial crisis period in an emerging market. Emerging Markets Review, 7(4), 320-338.

Baskin, J. (1987). Corporate liquidity in games of monopoly power. The Review of Economics and Statistics, 312-319.

Bates, T. W., Kahle, K. M., \& Stulz, R. M. (2009). Why do US firms hold so much more cash than they used to?. The Journal of Finance, 64(5), 1985-2021.

Beaver, W., Lambert, R., \& Morse, D. (1980). The information content of security prices. journal of Accounting and Economics, 2(1), 3-28.

Dechow, P. M. (1994). Accounting earnings and cash flows as measures of firm performance: The role of accounting accruals. Journal of accounting and economics, 18(1), 3-42.

Dechow, P. M., \& Dichev, I. D. (2002). The quality of accruals and earnings: The role of accrual estimation errors. The accounting review, 77(s-1), 35-59.

Dechow, P. M., Richardson, S. A., \& Sloan, R. G. (2008). The persistence and pricing of the cash component of earnings. Journal of Accounting Research,46(3), 537-566.

Deshmukh, S., \& Vogt, S. C. (2005). Investment, cash flow, and corporate hedging. Journal of Corporate Finance, 11(4), 628-644.

Dopuch, N., Mashruwala, R., Seethamraju, C., \& Zach, T. (2005). Accrual determinants, sales changes and their impact on empirical accrual models. Working paper, Washington University in St. Louis.

Jiang, G. (2007). Stock performance and the mispricing of accruals. The International Journal of Accounting, 42(2), 153-170. 
Keynes, J.M. (1936). The General Theory of Employment Interest and Money. London, Macmillan Keynes, JM 1937A.

Mishkin, F. S. (1986). A rational expectations approach to macroeconometrics: Testing policy ineffectiveness and efficient-markets models. University of Chicago Press.

Ozkan, A., \& Ozkan, N. (2004). Corporate cash holdings: An empirical investigation of UK companies. Journal of Banking \& Finance, 28(9), 2103-2134.

Richardson, S. (2003). Earnings quality and short sellers. Accounting Horizons, 49-61.

Richardson, S. A., Sloan, R. G., Soliman, M. T., \& Tuna, I. (2005). Accrual reliability, earnings persistence and stock prices. Journal of Accounting and Economics, 39(3), 437-485.

Sloan, R. (1996). Do stock prices fully reflect information in accruals and cash flows about future earnings?. The Accounting Review, 71,289-315. 